\title{
SIMAA: um simulador em realidade virtual para o adestramento de artilharia
}

\author{
Álan J. C. Andrade \\ Departamento de Informática / PUC-Rio \\ Rio de Janeiro, Brasil \\ aandrade@tecgraf.puc-rio.br
}

\author{
Greis Silva-Calpa \\ Instituto Tecgraf / PUC-Rio \\ Rio de Janeiro, Brasil \\ greis@tecgraf.puc-rio.br
}

\author{
Alberto Barbosa Raposo \\ Departamento de Informática / PUC-Rio \\ Rio de Janeiro, Brasil \\ abraposo@tecgraf.puc-rio.br
}

\begin{abstract}
Resumo-Atualmente os simuladores de Artilharia têm ganhado grande visibilidade e importância, visto que oferecem uma nova forma à preparação e ao treinamento militar. Nesse cenário, os simuladores de Realidade Virtual (RV) se destacam porque possibilitam a imersão do usuário num ambiente virtual, onde pode atingir diferentes objetivos e treinamentos de situações reais. Entretanto, ainda encontram-se algumas dificuldades para o emprego de simuladores, principalmente as tecnologias adotadas que comprometem características de usabilidade, como discrepâncias em relação à realidade, além da falta de integração de subsistemas considerados essenciais, como observação e linha de fogo. Este trabalho visa identificar as limitações existentes nos simuladores de Artilharia, bem como os problemas de usabilidade, com o intuito de desenvolver um simulador em RV que supra tais limitações. Após seu desenvolvimento, o simulador será avaliado para identificar sua contribuição e viabilidade junto ao Grupo de Artilharia do Centro de Instrução Almirante Sylvio de Camargo, no Rio de Janeiro.
\end{abstract}

Index Terms-Adestramento Militar, Simulador de Artilharia, Realidade Virtual, Usabilidade

\section{InTRODUÇÃO}

As Forças Armadas no Brasil ${ }^{1}$ possuem um papel fundamental na defesa do país, capazes de assegurar os meios necessários para capacitação de suas forças de defesa com efetividade e competência [1]. Dentre essas forças encontrase a Artilharia de Campanha ou, simplesmente, Artilharia que visa apoiar a força terrestre através do fogo, destruindo ou neutralizando alvos que ameaçam o sucesso de determinadas operações [2].

Para o sucesso das operações, em que se obtenha os efeitos desejados, a Artilharia engloba alguns subsistemas; entre eles o subsistema de observação, responsável da localização dos alvos e condução de tiro, e o subsistema de Linha de Fogo (LF) que trata da escolha da posição e da colocação das peças [2] [3]. Esses subsistemas devem estar devidamente alinhados, pois estão diretamente relacionados com o problema técnico fundamental da Artilharia ${ }^{2}$.

$\mathrm{O}$ adestramento das funções que refletem nos subsistemas supracitados, pode ser otimizado através do emprego da simulação, [2] [4] utilizando sistemas de simulação ou

\footnotetext{
${ }^{1}$ Art. 142. As Forças Armadas, constituídas pela Marinha, pelo Exército e pela Aeronáutica, são instituições nacionais permanentes e regulares, organizadas com base na hierarquia e na disciplina [1].

${ }^{2} \mathrm{O}$ problema técnico fundamental consiste em manter a segurança da Artilharia, colocando seu material desenfiado, fora das vistas do inimigo [3].
}

simuladores, que procuram internalizar determinadas tarefas imitando um evento real através de um modelo, possibilitando ao combatente desempenhar com segurança atividades perigosas e tomar decisões de alto nível [5].

Entre os simuladores de Artilharia existentes, encontramos dois tipos, 1) simuladores para desktop [2] [6] [7] que consistem em softwares usados em computador onde a interação é por meio de dispositivos tradicionais, como mouse e teclado, e 2) simuladores em Realidade Virtual (RV) [8] que fazem uso de recursos imersivos, como HMDs (Head Mounted Displays), atuadores de movimentos, entre outros. Esses simuladores ainda possuem dificuldades no seu emprego, principalmente às tecnologias adotadas que comprometem características de usabilidade, como discrepâncias em relação à realidade, além da falta de integração de subsistemas considerados essenciais, como observação e LF.

Contextualizando este cenário, apesar de que já existam simuladores de Artilharia baseados em RV [8], é relevante o desenvolvimento de um simulador que explore as possibilidades da RV com o intuito de mitigar as limitações que existem atualmente, principalmente as relacionadas com usabilidade, que contribui ao usuário atingir metas em contextos específicos de uso, referentes a eficácia, eficiência e satisfação [9]. É, portanto, que propomos o presente trabalho.

\section{MotivaÇÃo}

Ainda com as dificuldades encontradas, os simuladores de RV apresentam vantagens sobre os simuladores de desktop, pois eles permitem criar uma imersão, possibilitando ao usuário interagir com um mundo virtual programado, trazendo benefícios para o seu aperfeiçoamento [10].

Através dos simuladores os treinamentos de Artilharia podem tornar-se mais realistas, os oficiais teriam a possibilidade de executar formas mais participativas de interagir com o ambiente, instigar o uso de diferentes formas sensoriais para interação e aprendizagem que não são possíveis de forma tradicional, além de criar um ambiente seguro para a realização de tarefas [4] [10].

\section{TRabalhos Relacionados}

Baseando-se em critérios específicos sobre características de usabilidade de simuladores de adestramento de Artilharia, a seguir são apresentados alguns dos trabalhos relacionados: 
Moreira [8] testou o Simulador em RV de Adestramento do Observador de Artilharia (SAOA), onde mostrou que o SAOA atingiu valores de referência para sensação de presença e eficácia. Como essa solução foi satisfatória, ela foi generalizada para o framework de RV IME. Entretanto, Moreira [8] aponta que em sua proposta não foram incluídos HMDs de alta resolução, não permitindo a implementação de experiências de $\mathrm{RV}$ com a maior qualidade visual possível.

Menin et al. [11] avaliaram a eficácia, a usabilidade e a imersão de 46 ambientes de jogos sérios com RV, incluíndo aplicações de treinamento militar. Os autores destacam que a RV melhora os resultados da simulação, como o aumento do ganho na aprendizagem e a retenção do conhecimento. No entanto, eles encontraram limitações como enjoo e acesso restrito ao hardware de RV.

\section{SIMAA - Simulador EM REALIDAdE ViRTUAL PARA Adestramento DE ARTIlHaria}

O SIMAA é composto por 3 (três) terminais: o terminal em RV do observador, o terminal desktop do instrutor e uma solução de sensores distribuídos nas peças da LF. A interação entre os terminais é dada de acordo com a Figura 1.

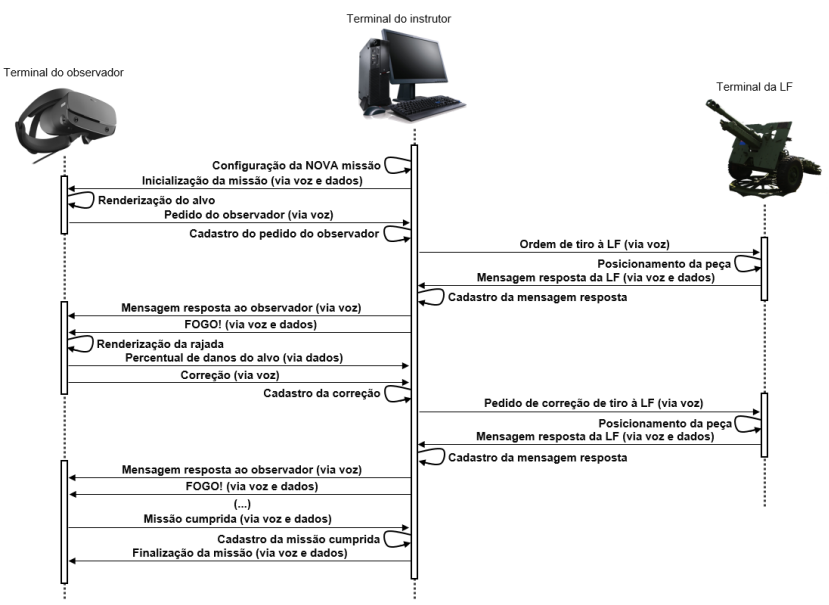

Figura 1. Diagrama de interação do SIMAA, adaptado de Moreira [8]

Para realizar o estudo de usabilidade do SIMAA, será utilizada uma amostra com os militares do Batalhão de Artilharia do Centro de Instrução Almirante Sylvio de Camargo (CIASC), localizado no Rio de Janeiro. Os dados do estudo serão coletados a partir de dois propósitos:

1) Verificar a usabilidade e experiência dos participantes a respeito do simulador;

2) Avaliar a aplicação do simulador no âmbito da defesa nacional e sua contribuição no adestramento de artilharia.

Os propósitos definidos para a avaliação deste estudo são refletidos em duas abordagens:

- Abordagem Qualitativa: para esta aborgem pretende-se aplicar um Questionário específico ao nosso estudo, além da aplicação do Protocolo Think Aloud, para reforçar os resultados encontrados durante os testes.
- Abordagem Quantitativa: para esta abordagem pretende-se realizar testes de usabilidade com o intuito de avaliar parâmetros de especificação referentes a (i) percepção geral de presença, (ii) presença espacial, (iii) envolvimento e (iv) realismo do ambiente de RV.

\section{CONClus Ão}

$\mathrm{Na}$ realização deste estudo esperamos apresentar um simulador que ofereça um ambiente em RV que permita o adestramento militar de maneira eficiente, efetiva e atraente; com caracteísticas apropriadas ao Grupo de Artilharia do CIASC. Pretendemos também contribuir no estado da arte com um conjunto de requisitos que possam ser considerados por outros autores para projetar simuladores em RV, além de incentivar pesquisa e desenvolvimento de simuladores de Artilharia em âmbito nacional.

Como resultados preliminares identificamos um conjunto de características que comprometem a usabilidade dos simuladores de Artilharia, onde desenvolvemos nossa aplicação com o intuito de suprir essas necessidades. Além disso construímos um modelo conceitual para a integração dos subsistemas de observação e LF, visando um treinamento mais efetivo.

\section{REFERÊNCIAS}

[1] P. Ferreira; R. Barros. O papel das Forças Armadas na Defesa Nacional. 2016. 22 f. Artigo de conclusão de iniciação científica. Universidade de Uberaba, Uberaba-MG: 2016.

[2] F. Costa. A utilização do simulador de tiro FATS 4 no adestramento do observador de artilharia de campanha. 2009. 36 f. Artigo Científico (Mestrado em Operações Militares) Escola de Aperfeiçoamento de Oficiais, Rio de Janeiro, 2009.

[3] BRASIL. Ministério da Defesa. C 6-40 - Manual de campanha: técnica de tiro de Artilharia de Campanha. Vol. 1. 5 ed. Brasília: Exército Brasileiro, 2001.

[4] K. M. Kapp; L. Blair; R. Mesch. The Gamification of Learning and Instruction Fieldbook - ideas into Practice. Wiley: San Francisco, CA. 2014.

[5] A. Teixeira. Centro de simulação de Artilharia de Campanha: a tecnologia em apoio à formação e ao adestramento do artilheiro. 2003. 123 f. Dissertação (Mestrado em Operações Militares) - Escola de Aperfeiçoamento de Oficiais, Rio de Janeiro, 2003.

[6] L. Stecanella. A influência da simulação no preparo técnico do observador: um estudo sobre a modernização no adestramento da observação do tiro de artilharia. 2017. 44 f. Monografia de Graduação (Bacharelado em Ciências Militares) Academia Militar das Agulhas Negras, Resende, 2017.

[7] N. Freitas Júnior. O impacto do simulador de apoio de fogo-sul no adestramento dos grupos de artilharia de campanha: um enfoque no subsistema linha de fogo. 2019. 29 f. Artigo Científico (Especialização em Ciências Militares) Escola de Aperfeiçoamento de Oficiais, Rio de Janeiro, 2019.

[8] R. Moreira. A aplicação da realidade virtual no adestramento do observador de artilharia e generalização da solução com o framework $I M E^{V R}$. 2019. 67 f. Dissertação de Mestrado (Mestrado em Sistemas e Computação) Instituto Militar de Engenharia, Rio de Janeiro, 2019.

[9] D. Alonso-Ríos; A. Vázquez-García; E. Mosqueira-Rey; V. MoretBonillo. Usability: A Critical Analysis and a Taxonomy. International Journal of Human-Computer Interaction, 26:1, 53-74, 2010. DOI: 10.1080/10447310903025552

[10] V. Nassar; C. Canheti; A. Salomão; J. Nishida; M. Vieira. A experiência do usuário com um simulador de realidade virtual para treinamento militar especializado. Proceedings of the 9th CIDI and 9th CONGIC. Belo Horizonte, 2019.

[11] Menin, A.; Nedel, L.; Torchlsen, R. An analysis of vr technology used in immersive simulations with a serious game perspective. IEEE Computer Graphics and Applications, v. 38, n. 2, p. 57-73, mar. 2018. 